\title{
Algılanan Sosyal Kaytarmanın Örgütsel Adalete Etkisi: Politik Davranışın Düzenleyici Rolü
}

\author{
Kemal KÖKSAL ${ }^{1}$
}

Öz

Sosyal kaytarma, bireyin tek başına ortaya koyduğu performansı grup halinde çalışırken göstermeme eğilimidir. Algılanan sosyal kaytarma ise bir çalışanın diğer çalışma arkadaşlarının sosyal kaytarma yapıp yapmadığına yönelik algısıdır. Çalışmada algılanan sosyal kaytarma ile örgütsel adalet algısı arasındaki ilişki ve bu ilişkide politik davranışın düzenleyici rolü incelenmiştir. Değişkenler arasındaki ilişkiyi test etmek amacıyla, büyük ölçekli bir kamu kurumunda çalışan 231 kişiden kolayda örneklem yöntemiyle veri toplanmıştır. Araştırmanın bulgularına göre sosyal kaytarma algısı örgütsel adaletin bir öncelidir ve politik davranış sosyal kaytarma ile örgütsel adalet algısı arasındaki ilişkide düzenleyicilik etkisine sahiptir.

Anabtar Kelimeler: Sosyal kaytarma alg1sı, Örgütsel adalet, Politik davranış, Düzenleyici etki

\section{The Effect of Perceived Social Loafing on Organizational Justice: The Moderating Role of Political Behavior}

\section{Abstract}

Social loafing is propensity for individuals to strive less energy when employing in groups rather than individually. Perceived social loafing is an employees' perception of whether or not his or her co-worker making less energy when employing in a group. In this study, the relationship between the perception of social loafing and organizational justice and the moderating role of political behavior were examined. To test the relationship among the factors, data were gathered from 231 people working in a large-scale public institution by the convenience sampling method. According to results, the perception of social loafing is an antecedent of the organizational justice and, political behavior has a moderate effect on the relationship between perceived social loafing and organizational justice.

Key Words: Perceived social loafing, Organizational justice, Political behavior, Moderating effect

Atıf İçin / Please Cite As:

Köksal, K. (2020). Alg1lanan sosyal kaytarmanın örgütsel adalete etkisi: Politik davranışın düzenleyici rolü. Manas Sosyal Araşttrmalar Dergisi, 9(3), 1750-1761.

Geliş Tarihi / Received Date: 12.02.2019

Kabul Tarihi / Accepted Date: 17.04.2020

\footnotetext{
${ }^{1}$ Dr.Öğr. Üyesi - Türkiye, Akdeniz Üniversitesi Serik İşletme Fakültesi, kemalkoksal@akdeniz.edu.tr ORCID: 0000-0001-7653-1762
} 


\section{Giriş}

Örgütsel adalet, çalışanların, örgütteki ödül ve cezaların dağıtımına, bu dağıtıma nasıl karar verildiğine ve yöneticilerle olan ilişkilerin niteliğine göre oluşan bir algıdır (Colquitt vd., 2013). Örgütsel adalet algıs1 çalışanların örgütsel bağlllık, örgütsel vatandaşlık, psikolojik sermaye, işten ayrılma niyeti, aykırı işyeri davranışı, devamsızlık gibi tutum ve davranışlarını etkileyen önemli bir değişkendir (Cohen-Charash ve Spector, 2001; Harris, Andrews ve Kacmar, 2007; Colquitt vd., 2013; Colquitt, Long, Rodell ve HalvorsenGanepola, 2015; Mert ve Şen, 2019). Örgütsel adalet algısının çalışan tutum ve davranışları üzerindeki etkisinden dolayı nasıl oluştuğunun anlaşılması ve öncellerinin bilinmesi, örgütsel etkinliğin artırılması için önemli bir konudur.

Sosyal kaytarma, bireyin normalde gösterdiği performansı grup halinde çalışırken göstermemesi olarak tanımlanmaktadır (George, 1992). Algılanan sosyal kaytarma ise diğer çalışma arkadaşlarının grup içinde normalde gösterebileceklerinden daha az çaba gösterdiklerine yönelik çalışan algısıdır (Comer, 1995). Sosyal kaytarma ve algılanan sosyal kaytarma birbirinden farklı kavramlar olarak karşımıza çıkmaktadır. Sosyal kaytarma bireyin normalde gösterebileceğinden daha az çaba göstermesi olarak kavramsallaştırarak, bunun nedenleri ve sonuçları çok sayıda araştırmanın konusu olurken; diğer çalışma arkadaşlarının yaptıkları sosyal kaytarmaya yönelik algıyı, diğer bir ifadeyle algılanan sosyal kaytarmayı ve bunun örgütsel sonuçlarını inceleyen çalışmaların sayısı sınırlı kalmıştır. Çalışmalarla, algıllanan sosyal kaytarmanın grup performansını olumsuz etkilediğini, çalışanların motivasyonunu azalttığını (Mulvey ve Klein, 1998), grup üyelerinin tatminini azalttı̆̆ını (Wall ve Nolan, 1987) ve örgütsel sinizmi artırdığını (Yakın ve Sökmen, 2018) tespit edilmiştir.

Politik davranış, farklı çıkar gruplarında, bireylerin güç kazanmak ve kendi çıkarını korumak amacıyla gösterilen davranış olarak ifade edilebilir (Ferris vd., 2007). Politik davranış diğer çalışanların örgütsel bağıllığını ve iş tatminini azaltma, işten ayrılma niyetini artırma gibi örgütün zararına olabilse de, bireyin çıkarına yönelik davranışlardır (Gandz ve Murray, 1980). Çalışanlar dağıtım kararlarını kendi lehlerine değiştirmek, ceza ve istenmeyen görevlerden kaçınmak amacıyla politik davranma eğiliminde olabilmektedir.

Özellikle büyük ölçekli kamu örgütlerinde çalışan sayısının çok olması, çalışma gruplarını büyüterek ve görev görünürlügünü azaltarak sosyal kaytarma davranışını kolaylaştıran bir neden olarak (Liden, Wyne, Jaworski ve Bennett, 2004) karşımıza çıkmaktadır. Çalışma arkadaşlarının normalde göstereceğinden daha az çaba gösterdiğini algılayan çalışan "enayi durumuna" (sucker effect) düşmemek amaciyla kendi çabasını azaltabilmektedir (Kerr, 1983). Bu durumun olumsuz sonuçlarından kaçınmak ve yöneticisinin dağıtım kararlarını kendi lehine etkilemek amacıyla çalışanlar politik davranış gösterebilirler.

Çalışma arkadaşlarının normalden daha az çaba gösterdiğini algılayan çalışanın, örgütsel adalet algisının bu durumdan nasıl etkilendiği ve politik davranma becerisinin, algilanan sosyal kaytarma ve örgütsel adalet ilişsisindeki rolünün araştırılması bu çalışmanın konusunu oluşturmaktadır.

\section{Alg1lanan Sosyal Kaytarma Örgütsel Adalet İlişkisi}

Örgütsel adalet, kazanımların dağglımına, bu dağılım sürecinde uygulanan işlemlere ve yöneticilerin davranışlarına göre oluşan çalışan algıllarını ifade etmektedir (Cohen-Charash ve Spector, 2001). Bu konuda yapılmış çalışmaların çoğu Adams'ın (1965) eşitlik kuramına dayanmaktadır. Kuramda bireylerin kendi katk1 ve kazanımlarını, diğerlerinin katkı ve kazanımları ile değerlendirerek adalet algısını oluşturduğu ifade edilmektedir. Adams'ın kazançların dağıtımına yönelik oluşturduğu kuram dağıtım adaleti olarak isimlendirilmiştir. Daha sonra dağıtım kararlarındaki süreçlerin adilliğine ilişkin algılanı içeren süreç adaleti (Folger ve Konovsky, 1989) kavramsallaştırılmıştır. Yöneticilerin çalışanlarla kurdukları etkileşimin adilliğine yönelik algilar ise etkileşim adaleti olarak ilgili alan yazında yer almıştır (Folger ve Cropanzano, 2001). Örgütsel adalet algısı çok sayıda örgütsel tutum ve davranışla ilişkili (Colquitt vd., 2013; Colquitt, Long, Rodell ve Halvorsen-Ganepola, 2015) olduğundan örgütsel adaletin oluşmasinda etkili olan faktörlerin ortaya çıkarılması önemlidir.

Sosyal kaytarma, bireyin tek başına gösterebildiği normal performansı grup içindeyken düşürmesi olarak ifade edilmektedir (George, 1992). Grup içindeki düşünsel ve fiziksel sosyal kaytarmanın oluşumu, sosyal kaytarmanın nedenleri ve engellenmesi, grup üyelerinin sosyal kaytarmaya adaptasyonu, sosyal kaytarmanın pozitif yanları ve günümüz teknolojisinde sosyal kaytarma konularının çalışmalarda incelendiği görülmektedir (Alnuaimi, Robert ve Maruping, 2010; Simms ve Nichols, 2014; Etemadi, 
Darab, Khorasani, Moradi ve Vazirinasab, 2015). Sosyal kaytarma konusunda yapılan çalışmalar incelendiğinde görev görünürlüğü, bağımlıllı̆̆ı, işin ve bireyin işe katkısının önemi ve adalet algısının (Liden, Wyne, Jaworski, ve Bennett 2004) araştırmacılar tarafindan sosyal kaytarmanın nedenleri olarak incelendiği görülmektedir. Ulusal yazınımızda Büyük Beş Kişilik özelliklerinden sorumluluğun (Tan ve Tan, 2008), kontrol odağı boyutlarından dış kontrol odağı, adil olmayan dünya inanc1 ve kişisel kontrolün (Erol, Beyaz ve Tinaz, 2018) işyeri nezaketsizliğinin (Kanten, 2014), işten ayrılma niyetinin (Akgündüz, Akdağ, Güler ve Sünnetçioğlu, 2014), izlenim yönetimi taktiklerinin (Yıldız, İşçi ve Taşçı, 2016), takım eğiliminde olmanın (Atilla Gök ve Koca, 2016), iş yaşamının kalitesini belirleyen adil ücret algısı ve işin yaşamda kapsadığı alan algısı boyutlarının (Kanten, Esirgemez, Aydın Hasekioğlu ve Keçeli, 2018) ve algılanan sosyal kaytarmanın (Şeşen, Soran ve Caymaz, 2014) sosyal kaytarma davranışını anlamlı bir şekilde yordadığı tespit edilmiştir. Bu çalışmada ele aldığımız örgütsel adaletin de sosyal kaytarma davranışının önemli bir önceli olduğu araştırmalar sonucu ortaya konulmuştur. Birey örgütünde, özellikle etkileşim ve dağitım adaletsizliği algıladığında, sosyal mübadele kuramı kapsamında (Blau, 1964) kendi çabasını azaltabilmektedir (Thanh ve Toan, 2018; Luo, Qu ve Marnburg, 2013; Liden, Wyne, Jaworski ve Bennett, 2004; George, 1992; Murphy, Wayne, Liden ve Erdogan, 2003). Uslu ve Çavuş (2014) yaptıkları çalışmada devlet üniversitesinde idari kadroda görev yapan personel üzerinde yaptıkları çalışmada sosyal kaytarma davranışının adalet algısı tarafindan önemli oranda açıkladığını tespit etmişlerdir.

Bu çalısmada, bireyin kendi kaytarma davranışından farklı olarak diğer çalışma arkadaşlarının yaptıkları kaytarmaya yönelik algılarının örgütsel adalet algısı üzerindeki etkisi incelenmektedir.

Sosyal öğrenme kuramı, bireylerin çevrelerini gözlemleyerek nasıl davranması gerektiğini öğrendiğini ifade etmektedir (Bandura, 2002). Örgütte, çalışma arkadaşlarının kaytardığını gören bireyin "enayi durumuna" düşmemek için bir süre sonra çabasını azaltarak sosyal kaytarma davranışı sergileyeceği ifade edilmektedir (Kerr, 1983). Ancak Williams ve Karau (1991) bütün grup üyelerinin bu şekilde tepki vermediğini, bazılarının da kaytaranların göstermediği davranışı telafi etmek için (sosyal telafi / social compensation) çaba harcadığı sonucuna ulaşmıştır. Diğer çalışma arkadaşlarının göstermediği performans için fazladan çabalayan birey, diğer grup üyeleri ile aynı şekilde değerlendirildiğinde ya da fazladan gösterdiği çabanın karşılığını alamadığında, bireyde adaletsizlik algısı oluşabilecektir. Sosyal telafi kuramı (Williams ve Karau, 1991) kapsamında diğerlerinin göstermediği çaba için fazladan katkı sağlayan çalısanın, sosyal mübadele kuramı (Blau, 1964) çerçevesinde bu çabalarının karşıllğını alamadığını düşündüğünde adaletsizlik algısı yaşayabileceği değerlendirilmektedir. Ayıı birey diğer çalışma arkadaşlarının kaytardığını algiladığında, kendisi sosyal telafi kuramı kapsamında fazladan çaba göstermese bile, örgütsel sonuçların kaytarmaya rağmen aynı dağıtıldığını görmesi durumunda da eşitlik teorisi (Adams, 1965) çerçevesinde adalet algısının etkilenebileceği değerlendirilmektedir. Çünkü kaytaran çalışanlar ile kendi çabasını ve elde ettiği örgütsel sonuçların karşılaştırmasını yapacak ve bunun sonucunda adalet algisı oluşacaktır.

Alg1lanan sosyal kaytarmayla ilgili çalışmalar incelendiğinde çeşitli örgütsel değişkenlerle ilişkisi olduğu görülmektedir. Hung ve diğerleri (2009) algılanan sosyal kaytarmanın aykırı işyeri davranışının bir önceli olduğunu; Aydemir (2018) algılanan sosyal kaytarmanın çatışma eğilimi ile pozitif ilişkisi olduğunu ve çatışma eğilimini artırdığını tespit etmişlerdir. Hung ve diğerleri (2009) algilanan sosyal kaytarmanın aykırı işyeri davranışını artırdığını; Mulvey ve diğerleri (1998) savunmacı izlenim yönetimi ile pozitif ilişkisi olduğunu tespit etmişlerdir. Ulusal yazınımızda ise Himmetoğlu ve diğerleri (2018) politik davranışın alt boyutlarından meşrulaştırma ve baskının algılanan sosyal kaytarmanın önceli olduğunu bulmuşlardır. Atilla Gök ve Koca (2016) takım eğiliminin algılanan sosyal kaytarmayı negatif etkilediğini; Olcay ve diğerleri (2018) algılanan sosyal kaytarmanın yaş, gelir ve eğitim düzeyiyle ilişkili olduğunu tespit etmişlerdir. Sünnetçioğlu ve diğerleri (2014) toplulukçu kültürün algilanan sosyal kaytarmanın önceli olduğunu, Turunç (2015) iş stresiyle algılanan sosyal kaytarmanın ilişkili olduğunu göstermişlerdir.

Yukarıdaki teorik açıklamalar ve daha önceki çalışma bulgularından hareketle bir numaralı birinci hipotez aşağıdaki şekilde ifade edilmiştir.

H1: Algılanan sosyal kaytarma örgütsel adalet algısını anlamlı ve negatif bir şekilde etkilemektedir.

\section{Politik Davranışın Düzenleyici Rolü}

Politik beceri, işyerinde diğerlerini iyi bir şekilde anlamak ve bu bilgileri kişisel ve/veya örgütsel hedefleri için diğerlerini etkilemek amaciyla kullanma yeteneği anlamına gelmektedir (Ferris vd., 2007). Örgütler politik alanlar olduğundan (Pfeffer, 1981), bireyler kendi amaçlarına ulaşmak ya da kendi çıkarını maksimize etmek amacıyla politik davranabilmektedir. Bireyin ihtiyaçları, kişilik özellikleri ve motivasyonu 
politik davranışta etkili olan bireysel faktörlerken (Barbuto ve Scholl, 1999; Barbuto, Fritz ve Marx, 2002), örgütün büyüklüğü, türü, amaçlar ve bunların bireyle olan ilişki derecesi politik davranışı etkileyen örgütsel faktörlerdir (Hochwarter, Kacmar, Perrew ve Johnson, 2003). Bireylerin sayg1 görme, kabullenilme ve güç elde etme ihtiyaçları, Makyavelizm kişilik özelliği ve kariyer beklentileri politik davranışı artırırken, ilişki ihtiyacı, uyumluluk kişilik özelliği politik davranışı azaltabilmektedir. Politik davranma becerisi yüksek olan çalşsanların olumlu iş tutum ve davranışları geliştirirken, düşük olan (politik davranamayan) çalışanların ise olumsuz iş tutum ve davranışları geliştirdikleri tespit edilmiştir (Gupta ve Case, 1999; Cropanzano, Kacmar ve Bozeman, 1995; Cropanzano, Howes, Grandey ve Toth, 1997; Kipnis ve Schmidt, 1988; Wayne ve Kacmar, 1991).

Bireyin diğer çalışanların göstermediği performansı telafi etmesinin, bireyin özgeciliğine, işin önemine, grubun başarısızlı̆̆ını ya da başarısını bireyin kendisine atfetme durumuna bağlı olarak değiştiği ileri sürülmektedir (Williams ve Karau, 1991). Bu nedenlerden dolayı grup için fazladan çalışan birey, örgüt içindeki sosyal öğrenmenin de bir sonucu olarak, "enayi durumuna" düşen kişi olmak istememesinin de etkisiyle grup içindeki çabasını azaltırken, izlenim yönetimi yaparak yöneticilerin dağıtım kararlarını etkileyerek (Judge ve Bretz, 1994) dağıtım kararlarını adaletsiz olarak nitelendirmeyebilir. Yöneticilerinden yüksek performans değerlendirmesi ve terfi almak amacıyla, iş-yönetici odaklı (Farmer, Maslyn, Fedor ve Goodman, 1997) göze girme ve rasyonellik (Higgins, Judge ve Ferris, 2003) taktikleri gibi yukarı yönlü etkileme taktikleri kullanılabilmektedir. Buradan hareketle politik davranabilmenin algilanan sosyal kaytarmanın örgütsel adalete etkisini düzenleyici etkisi olduğu değerlendirilmektedir. Yukarıda açıklanan kuram ve araştırmalar sonucunda ikinci hipotez aşağıdaki gibi ifade edilmiştir:

H2: Sosyal kaytarma alg1sı söz konuyken, politik davranma yeteneği yüksek çalışanların örgütsel adalet algısı artmakta, düşük çalışanların örgütsel adalet alg1sı azalmaktadır.

\section{Yöntem}

$\mathrm{Bu}$ araştırma algilanan sosyal kaytarma ile örgütsel adalet değişkenleri arasındaki nedensel ilişkiyi araştıran bir araştırmadır. Araştırmada veriler kesitsel olarak, kolayda örneklem ve öz değerlendirme yöntemiyle elde edilmiştir. Değişkenler arasındaki ortak yöntem nedeniyle açıklanan varyans olup olmadı̆̆ Harman'ın tek faktör analizi ile incelenmiştir. Anket formunda yer alan bütün ifadeler bir faktör altında toplanmış ve rotasyona tabi tutulmadan açıklayıcı faktör analizi yapılmıştır. Bunun sonucunda açıklanan ortak varyans oran $\% 39$ 'dur. Bu sonuca göre ortak yöntem varyans sorunu olmadığı değerlendirilmiştir (Podsakoff, MacKenzie, Lee ve Podsakoff, 2003).

$\mathrm{Bu}$ araştırma kapsamında incelenen model Şekil 1'de gösterilmiştir.

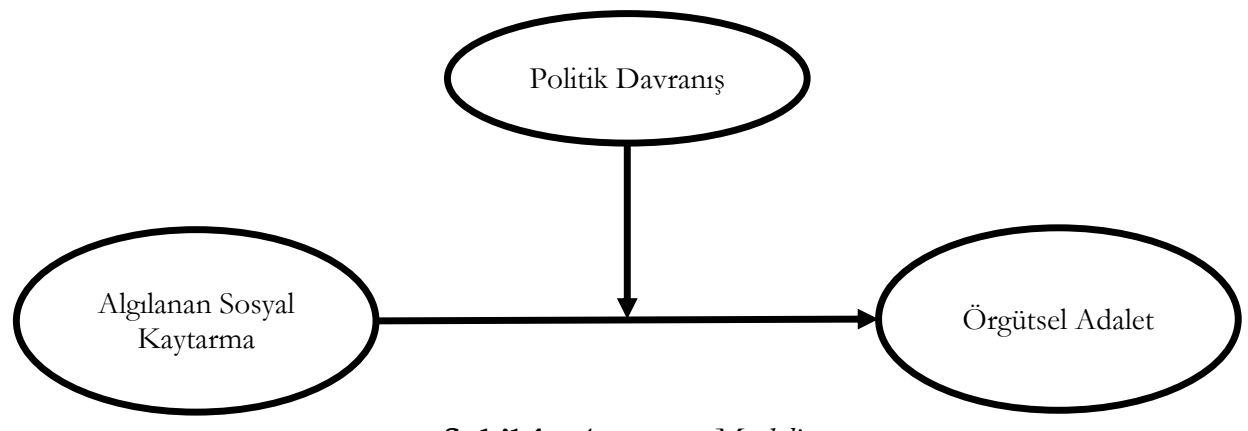

Şekil 1. Arașttrma Modeli

\section{Ölçekler}

$\mathrm{Bu}$ araştırmada kullanılan üç ölçek de beşli Likert (1=Tamamen katılmıyorum, 5=Tamamen katılıyorum) kullanılarak veriler toplanmışır. Çalışanların adalet algısını ölçmek için Moorman (1991) tarafindan geliştirilen örgütsel adalet ölģeğinin beş sorudan oluşan dağıtım adaleti boyutu kullanılmıştır. Ölçekte "Sahip olduğum deneyim ile aldığım ödüller birbirine uygundur." şeklinde ifadeler yer almaktadır. Sosyal kaytarma algısını ölçmek için ise George (1992) tarafindan geliştirilen sosyal kaytarma ölçeğinin, Güçer ve diğerleri (2017) tarafindan sosyal kaytarma algısını ölçecek şekilde uyarlanan biçimi kullanılmıştır. Tek boyut ve dokuz ifadeden oluşan ölçekte "Çalıştığım yerde, bazen ekipteki diğer çalışanlardan daha az çaba gösterenler vardır." şeklinde ifadeler yer almaktadır. Politik davramış ölçmek amacıyla Kipnis ve Schmidt (1988) tarafından geliştirilen ölçek kullanılmışır. Ölçekte "Üstümü ikna etmek için çalışma arkadaşlarımın 
desteğini alıım." şeklinde ifadeler vardır. Ölçek altı boyuttan ve 18 ifadeden oluşan bir ölçektir, fakat çalısmada genel olarak bireylerin politik davranışın düzenleyici etkisi araştırıldığı için tek boyutlu olarak ele alınmıştır.

\section{Örneklem}

Değişkenler arasındaki teorik ilişkiyi test etmek amacıyla kolayda örneklem ile 425 çalışanı olan büyük ölçekli bir kamu kurumundan veri toplanmıştır. Ülke genelinde kamu hizmeti sunan ve her ilde müdürlükleri bulunan bir kurumun genel müdürlüğünde araştırma yapılmıştır. Çok sayıda çalışanı bulunan kurumda, görev görünürlüğ̈nün azalmasının ve kontrole ilişkin problemler yaşanmasının muhtemel olması ayrıca çalışan sayısının fazla olduğu kamu kurumlarında etkileme taktiklerinin özellikle de göze girme taktiğinin fazla kullanılması (Özdemir Yaylac1, 2006) nedeniyle örneklem olarak büyük ölçekli kamu kurumunun seçilmesine karar verilmiştir. Birinci bölümde katılımcıların cinsiyeti, yaş, medeni durumu ve eğitim durumunun; ikinci bölümde araştırma değişkenlerine ilişkin ifadelerin yer aldığ1 anket formu, araştırmacılar tarafindan elden dağıtılmış ve tekrar elden toplanmıştır. Araştırmanın amacı çalışanlara birebir açıklanarak katılımcıların kimlik bilgililerinin istenmediği, isteyenlerle araştırma bulguların paylaşılacağı ifade edilmiştir. Dağıtılan 300 anketten 266 anket formu geri alınabilmiştir. Anketlerin geri dönüş oranı \%88,7'dir. Toplanan anketlerden uç verilerin ve uygun doldurulmayan anketlerin analizden çıkarılması sonucunda 231 veriyle analiz gerçekleştirilmiştir. Çalışmaya katılanların demografik bilgileri Tablo 1'de gösterilmiştir.

Tablo 1. Demografik Bilgiler

\begin{tabular}{|c|c|c|c|}
\hline & & $\boldsymbol{N}$ & Yüzde \\
\hline \multirow{2}{*}{ Cinsiyet } & Erkek & 145 & 62,8 \\
\hline & Kadin & 86 & 37,2 \\
\hline \multirow{3}{*}{ Eğitim Durumu } & Lise & 54 & 23,4 \\
\hline & Lisans & 165 & 71,4 \\
\hline & Lisansüstü & 12 & 5,3 \\
\hline \multirow{5}{*}{ Yaş } & $20-24$ & 20 & 8,6 \\
\hline & $25-29$ & 77 & 33,5 \\
\hline & $30-34$ & 47 & 20,2 \\
\hline & $35-39$ & 54 & 23,4 \\
\hline & 40 ve üstü & 33 & 14,3 \\
\hline \multirow{2}{*}{ Medeni Durum } & Evli & 165 & 71,4 \\
\hline & Bekâr & 66 & 28,6 \\
\hline
\end{tabular}

\section{Ölçüm Modelleri}

Araştırmanın verilerini toplamak için kullanılan ölçeklerin yapı geçerlilikleri doğrulayıcı faktör analizi (DFA) ile güvenilirlikleri ise Cronbach Alpha ile kontrol edilmiştir. Ölçeklerin yapı geçerliliği bileşim ve ayrışım geçerlilikleriyle kontrol edilmiştir. Bileşim geçerliliği kapsamında ölçeklerdeki her bir ifadenin standardize katsayıları ve açılanan ortalama varyans değerleri incelenmiştir. Sosyal kaytarma algısını ölçmek için kullanılan ifadelerin standardize edilmiş regresyon yükleri 0,73 ile 0,92 arasındadır. Dağıtım adaleti ölçeğindeki ifadelerin standardize edilmiş regresyon yükleri 0,67 ile 0,88 arasında, politik davranış ölçeğindeki ifadelerin standardize edilmiş regresyon yükleri ise 0,75 ile 0,88 arasındadır. Açılanan ortalama varyans değerleri ise sosyal kaytarma algısının 0,735 , dağıtım adaleti algısının 0,633 ve politik davranışın ise 0,668 değerindedir (Hair, Black, Babin ve Anderson, 2010). Bu sonuçlara göre ölçeklerin benzeşim geçerliliklerinin iyi olduğu görülmektedir. Bileşik güvenilirlik değerleri ise sırasıyla $0,961,0,895$ ve 0,973 'tür. Ölçeklerin bileşik güvenilirlikleri de iyi seviyededir. Paylaşılan toplam varyans oranları ise sırasıyla 0,434 , 0,011 ve 0,08 'dir. Ayrışım geçerliliği olup olmadığ ise açıklanan ortalama varyans oranları ile paylaşılan varyans oranlanı karşılaştırılarak değerlendirilmiş̧ir. Paylaşılan ortak varyans değerleri açıklanan ortalama varyans oranlarından düşük olduğundan ölçeklerin farklı yapıları ölçtüğü değerlendirilmiştir (Hair, Black, Babin ve Anderson, 2010). Son olarak ölçeklerin iç tutarllıkları (Cronbach Alpha) ise sırasıyla 0,960, 0,888 ve 0,973 'tür. Ölçeklerin güvenilirliklerinin yüksek olduğu görülmüsstür.

Daha önceki çalışmalarda oluşturulmuş teorik modellerinin, örneklem kapsamında da aynı şekilde çalışıp çalışmadığını kontrol etmek maksadıyla uyum iyilik değerleri incelenmiştir. Tablo 2'deki doğrulayıcı faktör analizi sonuçları ölçeklerin tek boyutlu yapılarının uyum değerlerinin kabul edilebilir seviyede olduğunu göstermektedir. Politik davranış ölçeğinin hem tek boyutlu hem de çok boyutlu birincil ve ikincil seviye DFA yapılarak uyum değerleri incelenmiştir. Hem tek boyutlu hem de çok boyutlu birincil ve ikincil seviye DFA sonuçlarının birbirine yakın kabul edilebilir seviyede uyum değerlerine sahip olduğu 
görülmektedir (Hair, Black, Babin ve Anderson, 2010). Daha önce de ifade edildiği gibi araştırmada politik davranışın düzenleyici etkisi incelendiğinden, tek boyutlu ölçeğin kullanılmasına karar verilmiştir.

Tablo 2. DFA Sonuçar

\begin{tabular}{|c|c|c|c|c|c|c|c|c|}
\hline Ölçek & $\chi^{2}$ & $s d$ & $\chi^{2 / s d}$ & $R M S E A$ & $\overline{C F I}$ & $G F I$ & $\mathbf{N F I}$ & $R M R$ \\
\hline $\begin{array}{c}\text { Referans değerleri } \\
(\mathrm{N}<250)\end{array}$ & $p>0,05^{*}$ & & $<5 *$ & $<0.08$ & $>0,97 *$ & $>0,95 *$ & $>95 *$ & $<0,08 *$ \\
\hline Sosyal Kaytarma & 71,644 & 27 & 2,653 & 0,086 & 0,979 & 0,941 & 0,967 & 0,024 \\
\hline Örgütsel Adalet & 11,465 & 5 & 2,293 & 0,076 & 0,990 & 0,980 & 0,983 & 0,034 \\
\hline Politik Davranıș (1. düzey) & 329,404 & 120 & 2,745 & 0,088 & 0,947 & 0,867 & 0,920 & 0,036 \\
\hline Politik Davranıs (2. düzey) & 360,527 & 129 & 2,795 & 0,089 & 0,942 & 0,856 & 0,912 & 0,038 \\
\hline Politik Davranış (tek boyut) & 356,792 & 134 & 2,663 & 0,086 & 0,936 & 0,862 & 0,913 & 0,037 \\
\hline
\end{tabular}

*Gözlenen değiskeen sayısinm 12'den kü̈ü̈k olduğu durumlarda

\section{Bulgular}

Verilerin analizinde SPSS ve AMOS programları kullanılmıștır. Değișkenler arasındaki ilişki Pearson korelasyon analiziyle, bağımsız değişkenin bağıml değişkeni yordama gücü regresyon analiziyle ve düzenleyicilik etkisi ise PROCESS makro (Hayes ve Matthes, 2009) yazılımılla test edilmiştir.

Tablo 3'te algilanan sosyal kaytarma, örgütsel adalet ve politik davranışa ait betimleyici istatistikler sunulmuştur. Ortalamalara bakıldığında sosyal kaytarma algisının ve örgütsel adalet algisının ortalama değerden (3) düşük olduğu görülmektedir. Politik davranış ortalaması ise yaklaşık olarak ortalama değerde çıkmıştır. Sosyal kaytarma algısı ile örgütsel adalet alg1sı arasında negatif ve anlamlı orta düzeyde bir bağ söz konusuyken politik davranışla anlamlı bir ilişki olmadığı görülmektedir. Örgütsel adalet ile politik davranış arasında ise pozitif ve anlamlı bir bağ söz konusudur.

Tablo 3. Betimleyici Istatistikler

\begin{tabular}{lcccc}
\hline \multicolumn{1}{c}{ Değigskenler } & Ort. & S.S. & 1 & 2 \\
\hline 1-Sosyal Kaytarma Alg1s1 & 2,711 & 0,962 & & \\
2-Örgütsel Adalet Alg1s1 & 2,429 & 0,871 & $-0,660^{* *}$ & \\
3-Politik Davranıș & 2,990 & 0,931 & $-0,119$ & $0,273^{* *}$ \\
\hline
\end{tabular}

$* * \mathrm{p}<0,01$

Araştırmanın hipotezleri regresyon analizi ile test edilmiştir. Tablo 4'teki regresyon analizi sonuçları incelendiğinde sosyal kaytarma algısının örgütsel adalet algısını negatif bir şekilde etkilediği görülmektedir $(\beta=-0,598, F=173,247, \mathrm{p}<0,001)$. Sosyal kaytarma alg1s1 örgütsel adalet algisındaki varyans değişiminin \%43’ünü açıklamaktadır. Politik davranışın düzenleyicilik etkisi incelenmek amacıyla regresyon analizinin ikinci aşamasında politik davranış ve standardize edilmiş değerlerin çarpılması sonucu oluşturulan etkileşim değişkeni modele dâhil edilmiştir. Etkileşim değişkeni eklendiğinde $\mathrm{R}^{2}$ 'deki değişimin anlamlı olduğu görülmektedir $\left(\Delta \mathrm{R}^{2}=0,030, \mathrm{~F}=22,139, \mathrm{p}<0,0001\right)$. Sonuçlar araştırmanın hipotezlerini desteklemektedir.

Tablo 4. Algulanan Sosyal Kaytarma ve Örgütsel Adalet İliskisinde Politik Davranısın Düzenleyiciliğine İliskin Analiz Sonuclar

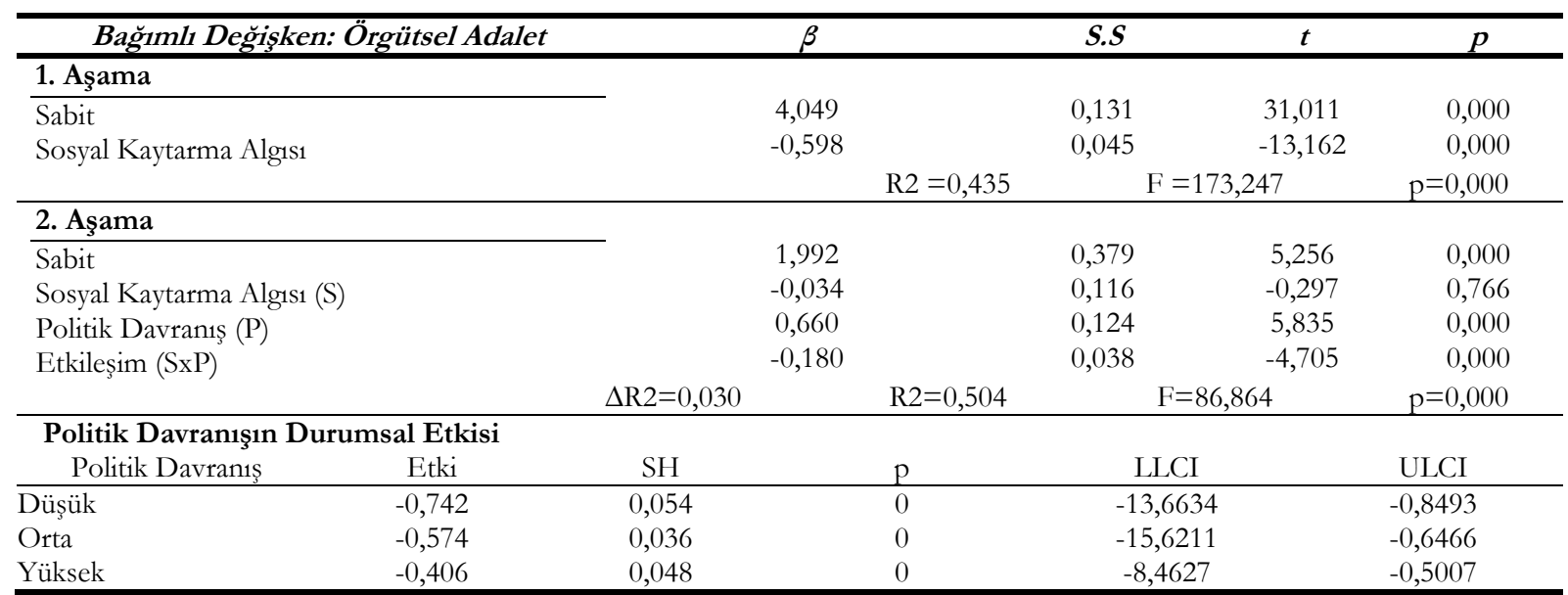

LLCI: Alt sinır güven aralı̆̆1, ULCI: Üst sınır güven aralığı 
Düzenleyicilik ilişkisinin anlamlı olması bu etkiyi yorumlamak için yetersizdir. Düzenleyici etkiyi yorumlayabilmek için ortalama değerlerden artı ve eksi bir standart sapmaya göre değişkenler arasındaki etkileşimlerin grafiğinin çizilmesi gerekmektedir (Şekil 2). Grafiğe göre bireylerin sosyal kaytarma algısı yükseldiğinde politik davranma becerisi yüksek çalısanların örgütsel adalet algisı artmaktadır. Tam tersi şekilde sosyal kaytarma algısı yükseldiğinde politik davranma becerisi düşük çalışanlar örgütlerini daha fazla adaletsiz algilamaktadır.

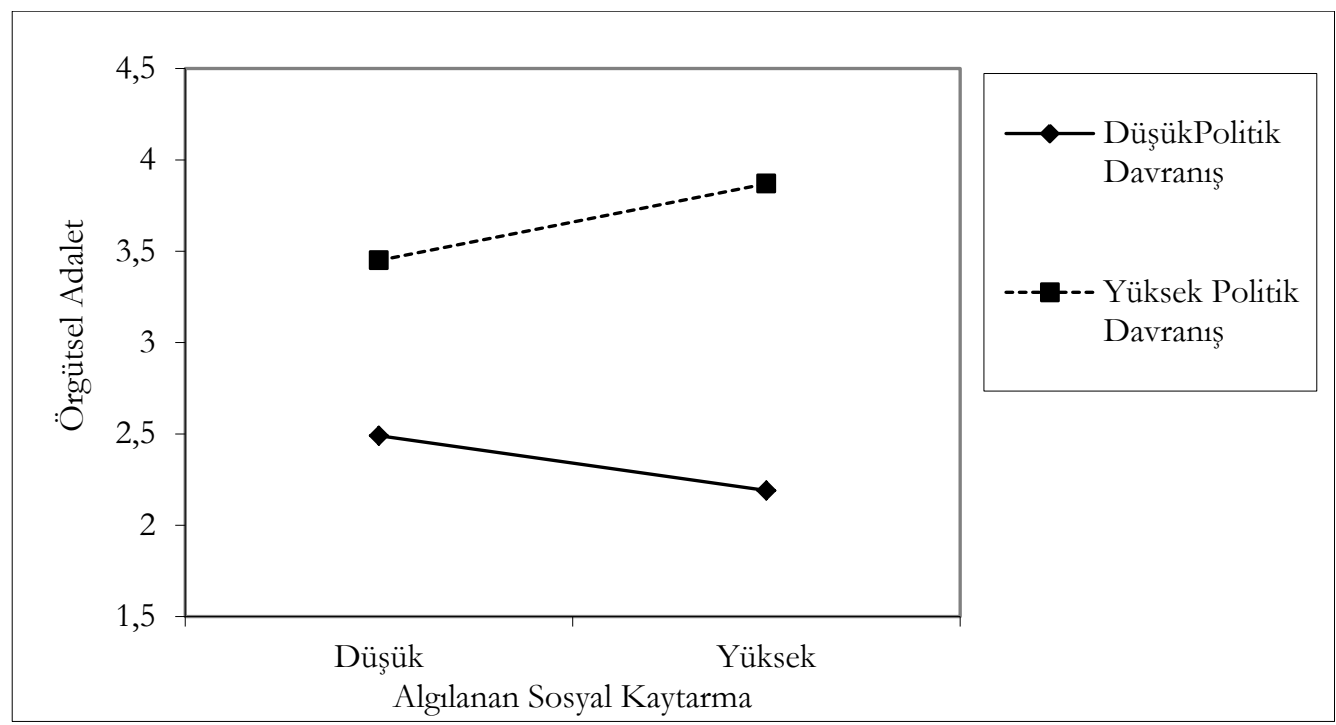

Şekil 2. Düzenleyici Etki Grafiği

\section{Tartışma, Sonuç ve Öneriler}

Çalışmada algılanan sosyal kaytarma ile örgütsel adalet algısı arasındaki ilişki ve bu ilişkide politik davranışın düzenleyici etkisi incelenmiştir. Araştırma bulgularına göre, katılımcıların genel olarak, örgütlerindeki sosyal kaytarma ve örgütsel adalet algılarının ortalamadan düşük; politik davranışın ise ortalamaya yakın olduğu görülmektedir.

Çalışma kapsamında algılanan sosyal kaytarmanın örgütsel adaleti negatif ve anlamlı bir şekilde yordadığı tespit edilmiştir. Bireyler örgütlerinde, çalışma arkadaşlarının kendi üzerine düşen görevleri yapmadıkları ya da normalde bireysel olarak gösterebileceği performansı grup içindeyken göstermediklerini düşündüklerinde, örgütsel adalet algisı bu durumdan negatif olarak etkilenmekte bir başka ifadeyle adaletsizlik algisı oluşabilmektedir.

Araştırmanın bir diğer sonucu da bireylerin politik davranma becerisinin algılanan sosyal kaytarma ile örgütsel adalet arasındaki ilişkiyi düzenlediğidir. Bu sonuca göre, sosyal kaytarma algısı yüksek olduğunda, politik davranma becerisi yüksek olan çalışanlanın örgütsel adalet alg1sı yükselmektedir. Politik davranma becerisi düşük olan çalışanlarda ise örgütsel adalet algısı azalmaktadır.

Araştırma bulguları örneklem kapsamında değerlendirildiğinde, katıllmcıların örgütsel adalet algılarının düşük olduğu görülmektedir. Bu sonuç katılımcıların, kurumlarındaki dağıtım kararlarını adaletsiz olarak gördükleri şeklinde yorumlanabilir. Ayrıca diğer çalışma arkadaşlarının kaytarma yaptığına yönelik algıları da düşüktür. Kurumdaki birlikte (takım) çalışma ortamının iyi olduğu ve herkesin üzerine düşen görevi yaptığı şeklinde yorumlanabilir. Politik davranışın ise ortalama seviyeye yakın algılandığ1 görülmektedir. Katılımcılar kurumlarında, çalısma arkadaşlarının kaytardığını algıladıklarında adalet algısı azalmaktadır. Algılanan sosyal kaytarmanın yüksek olması durumunda politik davranma becerisi yüksek olan çalışanlar, yöneticilerin dağıtım kararlarını etkileyerek, kurumlarını politik davranamayan çalışanlara göre daha fazla adaletli olarak algılayabilmektedir. Bu çalışmanın bulguları ile paralel olarak Şeşen ve diğerleri (2014) kamuda çalışan öğretmenler üzerinde yaptıkları araştırmada algılanan sosyal kaytarmanın örgütsel bağıllı̆̆ azalttığı ve bireyin kendi sosyal kaytarma davranışlarını artırdığını tespit etmişlerdir. Yakın ve Sökmen (2018) ise çeşitli sektörlerde çalş̧an 160 kişiden topladıkları verilerin analizi sonucunda algılanan sosyal kaytarmanın örgütsel sinizmi artırdığını tespit etmişlerdir. Uluslararası yazında Mulvey ve arkadaşları (1998) algılanan sosyal kaytarma ile savunmacı izlenim yönetimi taktikleri arasında pozitif ilişsi olduğunu tespit etmişlerdir. Bolino ve diğerleri ise (2008) izlenim yönetimi taktiklerinin, üretim karşıtı davranışlarının bir göstergesi olduğunu ifade emişlerdir. 
Önceki çalışmalar, örgütsel adaletin sosyal kaytarma davranışına neden olduğunu gösterirken, araştırma kapsamında, çalışma arkadaşlarının sosyal kaytarma yaptığına yönelik algının örgütsel adaletin zedelenmesindeki rolünü göstermesi açısından çalışmanın yöneticiler ve alanla ilgilenenlere katkı sağlayacağı değerlendirilmektedir. Örneklem kapsamında sonuçlar değerlendirildiğinde, kurum yöneticileri görevlerinin görünürlüğ̈̈nü artırarak ve bireysel performansları daha iyi değerlendirerek sosyal kaytarma algisını azaltabilirler (George, 1992; Simms ve Nichols, 2014). Böylelikle işten ayrılma niyetinde artış, örgütsel bağllık, vatandaşlık ve iş tatmininde azalış gibi çok sayıdaki olumsuz örgütsel sonucun önceli olan (Colquitt vd., 2013) adaletsizlik algısının oluşmasını engelleyebilirler. Ayrıca örgütler her ne kadar politik alanlar olsa da tüm çalışanların politik davranma becerisi olmadığından ve algılanan politik davranışın da (Ferris vd., 1996) işten ayrilma niyetinde artış, örgütsel bağlllıkta ve iş tatmininde azalış gibi olumsuz sonuçları olduğundan; politik davranışa neden olan kaynakların dağıtımı, örgütsel güven, personel değerlendirme sistemi, grup karar alma süreçleri ve örgütsel kurallar gibi örgütsel faktörleri (ayrıntı için Naji, Taboli, ve Zolfaghari, 2012) kontrol altına alarak olumsuz sonuçlarını azaltabilirler.

Bu çalışmanın bulguları ve sosyal kaytarma davranışıyla ilgili yapılan diğer çalışmaların bulguları bir bütün olarak değerlendirildiğinde, örgütsel adaletin sosyal kaytarmanın bir önceli olduğu (Greenberg, 1987; Liden, Wyne, Jaworski ve Bennett, 2004; Uslu ve Çavuş, 2014; Etemadi, Darab, Khorasani, Moradi ve Vazirinasab, 2015; Thanh ve Toan, 2018) ve algilanan sosyal kaytarmanın da örgütsel adaleti etkilediği görülmektedir. Liden ve arkadaşları (2004) ile Şeşen ve arkadaşlarının (2014) yaptıkları çalışmalarda ise algılanan sosyal kaytarma ile sosyal kaytarma davranışı arasında pozitif ilişki olduğunu tespit etmişlerdir. Önceki çalışmaların ve bu araştırmanın bir sonucu olarak, algılanan sosyal kaytarmanın örgütsel adaleti etkilediği, örgütsel adaletin de sosyal kaytarma davranışını dolaylı olarak etkilediği, algılanan sosyal kaytarma ile sosyal kaytarma davranışı arasında doğrudan bir ilişki olduğu görülmektedir. Bundan sonra yapılacak çalş̧malarda yukarıda bahsedilen ilişkiler ve politik davranışın algılanan sosyal kaytarma ile örgütsel adalet ve sosyal kaytarma davranışı arasındaki ilişkide düzenleyici etkisi araştırlabilir. Çalışmada verilerin kolayda örneklemle sadece bir kamu kurumundan toplanması araştırmanın bir kısıtıdır. Dolayısıyla ulaşılan sonuçlar genellenememektedir.

\section{Etik Beyan}

"Algzlanan Sosyal Kaytarmanın Örgütsel Adalete Etkisi: Politik Davramışın Düzenleyici Rolü” başlıklı çalışmanın yazım sürecinde bilimsel, etik ve alıntı kurallarına uyulmuş; toplanan veriler üzerinde herhangi bir tahrifat yapılmamış ve bu çalışa herhangi başka bir akademik yayın ortamına değerlendirme için gönderilmemiştir.

\section{Kaynakça}

Adams, J. S. (1965). Inequity In Social Exchange. R. Folger ve R. Cropanzano içinde, Organizational Justice and Human Resources Management (s. 1-4). London: Sage Publications.

Akgündüz, Y., Akdağ, G., Güler, O. ve Sünnetçioğlu, S. (2014). İșten ayrilma niyeti ve aşır1 rol yükünün otel çalşanlarının sosyal aylaklık davranışlarına etkisi. Dokuz Eylül Üniversitesi Sosyal Bilimler Enstitiisü Dergisi, 16(4), $515-536$.

Alnuaimi, O. A., Robert, L. P. ve Maruping, L. M. (2010). Team size, dispersion, and social loafing in technologysupported teams: A perspective on the theory of moral disengagement. Journal of Management Information Systems, 27(1), 203-230.

Atilla Gök, G. ve Koca, D. (2016). Sağlık çalışanlarında hiyerarşi ve takım eğiliminin sosyal kaytarmaya etkisi: Isparta ilçe hastaneleri örneği. Mehmet Akif Ersoy Üniversitesi Sosyal Bilimler Enstitiisï Dergisi, 8(17), 354-375.

Aydemir, S. (2018). Algılanan sosyal kaytarmanın örgütlerde çatışma eğilimine etkisi. MANAS Sosyal Araştımalar Dergisi, 7(2), 259-275.

Bandura, A. (2002). Social cognitive theory in cultural context. Applied Psychology: An International Review, 51(2), 269290.

Barbuto, J. E. ve Scholl, R. W. (1999). Leader's motivation and leader's perception of follower's motivation as predictors of leader's influence tactics. Psychological Reports, 84, 1087-1098.

Barbuto, J., Fritz, S. ve Marx, D. (2002). A field examination of two measures of work motivation as predictors of leaders influence tactics. The Journal of Social Psychology, 142(5), 601-616.

Blau, P. (1964). Exchange and power in social life. New York: Wiley.

Bolino, M. C., Kacmar, K. M., Turnley, W. H. ve Gilstrap, J. B. (2008). A multi-level review of impression management motives and behaviors. Journal of Management, 34, 1080-1109.

Cohen-Charash, Y. ve Spector, P. E. (2001). The role of justice in organizations: A meta-analysis. Organizational Behavior and Human Decision Process, 86(2), 278-321. 
Colquitt, J. A., Long, D., Rodell, J. B. ve Halvorsen-Ganepola, M. D. (2015). Adding the “in” to justice: A qualitative and quantitative investigation of the differential effects of justice rule adherence and violation. Journal of Applied Psychology, $100(2), 278-297$.

Colquitt, J. A., Scott, B. A., Rodell, J. B., Long, D. M., Zapata, C. P., Conlon, D. E. ve Wesson, M. J. (2013). Justice at the millennium, a decade later: A meta-analytic test of social exchange and affect-based perspectives. Journal of Applied Psycholog, 98, 199-236.

Comer, D. R. (1995). A model of social loafing in real work groups. Human Relations, 48, 647-667.

Cropanzano, R. S., Kacmar, K. ve Bozeman, D. (1995). Organizational politics, justice, and support: Their differences and similarities. R. Cropanzano ve K. Kacmar içinde, Organizational Politics, Justice and Support: Managing Social Climate at Work (s. 1-18). Westport: CT:Quorum Books.

Cropanzano, R., Howes, J. C., Grandey, A. A. ve Toth, P. (1997). The relationship of organizational politics and support to work behaviors, attitudes, and stress. Journal of Organizational Behavior, 18, 159-180.

Erol, Y., Beyaz, R. ve Tınaz, Z. D. (2018). Kontrol odağının sosyal kaytarma davranışı üzerindeki etkisi: sosyal hizmet kurumlarında bir araştırma. Journal of Social And Humanities Sciences Research, 5(25), 2374-2386.

Etemadi, M., Darab, M. G., Khorasani, E., Moradi, F. ve Vazirinasab, H. (2015). Social loafing among nurses and its relation with organizational justice. International Journal of Educational and Psychological Researches, 1(2), 125-130.

Farmer, S. M., Maslyn, J. M., Fedor, D. B. ve Goodman, J. S. (1997). Putting upward influence strategies in context. Journal of Organizational Behaviour, 18, 22-35.

Ferris, G. R., Treadway, D. C., Perrewé, P. L., Brouer, R. L., Douglas, C. ve Lux., S. (2007). Political skill in organizations. Journal of Management, 33, 290-320.

Folger, R. ve Cropanzano, R. (2001). Fairness theory: Justice as accountability. J. Greenberg ve R. Cropanzano içinde, Advances in Organizational Justice (s. 1-55). Stanford: CA: Stanford Univ. Press.

Folger, R. ve Konovsky, M. (1989). Effects of procedural and distributive justice on reactions to pay raise decisions. Academy of Management Journal, 35(1), 115-130.

Gandz, J. ve Murray, V. V. (1980). The experience of workplace politics. Academy of Management Journal, 23 (2), $237-$ 251.

George, J. M. (1992). Extrinsic and intrinsic origins of perceived social loafing in organizations. The Academy of Management Journal, 35(1), 191-202.

Greenberg, J. (1987). A taxonomy of organizational justice theories. Academy of Management Review „, 12, 9-22.

Gupta, S. ve Case, T. (1999). Managers' outward influence tactics and their consequences: an exploratory study. Leadership, Organizational Development Journal, 20, 300 - 311.

Güçer, E., Pelit, E., Demirağ, Ş. A. ve Keleş, Y. (2017). Sosyal kaytarmanın işten ayrılma niyeti üzerindeki etkisi: Otel işletmelerinde bir araştırma. Journal of Business Research Turk, 9(2), 14-36.

Hair, J. F., Black, W. C., Babin, B. J. ve Anderson, R. E. (2010). Multivariate data analysis: A global perspective (7 b.). New Jersey: Pearson Prentice Hall.

Hayes, A. F. ve Matthes, J. (2009). Computational procedures for probing interactions in OLS and logistic regression: SPSS and SAS implementations. Behavior Research Methods, 41, 924-936.

Higgins, C., Judge, T. ve Ferris, G. (2003). Influence tactics and work outcomes: A meta analysis. Journal of Organizational Behavior, 24, 89-106.

Himmetoğlu, B., Ayduğ, D. ve Terzi, Ç. (2018). Relationships between political behaviors of school principals and perceived coworkers' social loafing among teachers. Eurasian Journal of Educational Research, 76, 1-20.

Hochwarter, W. A., Kacmar, C., Perrew, P. L. ve Johnson, D. (2003). Perceived organizational support as a mediator of the relationship between politics perceptions and work outcomes. Journal of Vocational Behavior, 63, 438-456.

Hung, T., Chi, N. ve Lu, W. (2009). Exploring the relationships between perceived coworker loafing and counterproductive work behaviors: The mediating role of a revenge motive. Journal of Business and Psychology, 24(3), 257-270.

Judge, T. A. ve Bretz, R. (1994). Political influence behavior and career success. Journal of Management, 20, 43-65.

Kanten, P. (2014). İşyeri nezaketsizliğinin sosyal kaytarma davranışı ve işten ayrılma niyeti üzerindeki etkisinde duygusal tükenmenin aracılık rolü. Aksaray Üniversitesi İktisadi Ve İdari Bilimler Fakültesi Dergisi, 6(1), 11-26.

Kanten, S., Esirgemez, M., Aydın Hasekioğlu, Y. ve Keçeli, M. (2018). İş yaşaminin kalitesinin sosyal kaytarma ve işi erteleme davranişi üzerindeki etkisinde etik iklim algisinin rolü. Yönetim Bilimleri Dergisi, 16(32), 559-576.

Kerr, N. L. (1983). Motivation losses in small groups: A social dilemma analysis. Journal of Personality and Social Psychology, 45(4), 819-828.

Kipnis, D. ve Schmidt, S. M. (1988). Upward Influence Styles: Relationship with performance evaluations, salary, and stress. Administrative Science Quarterly, 33, 528-542.

Liden, R. C., Wyne, S. J., Jaworski, R. A. ve Bennett, N. (2004). Social loafing: A field investigation. Journal of Management, 30(2), 285-304.

Luo, Z., Qu, H. ve Marnburg, E. (2013). Justice perceptions and drives of hotel employee social loafing behavior. International Journal of Hospitality Management, 33, 456-464.

Mert, İ. S. ve Şen, C. (2019). Örgütsel destek, örgütsel adalet ve öz kendilik değerlendirmesinin psikolojik sermaye üzerindeki etkisi. Pamukekale Üniversitesi Sosyal Bilimler Enstitüsü Dergisi(36), 213-231.

Moorman, R. H. (1991). Relationship between organizational justice and organizational citizenship behaviors: Do fairness perceptions influence employee citizenship? Journal of Applied Psychology, 76(6), 845-855. 
Mulvey, P. W. ve Klein, H. J. (1998). The impact of perceived loafing and collective efficacy on group goal processes and group performance. Organizational Behavior And Human Decision Processes, 74(1), 62-87.

Mulwey, P. W., Bowes-Sperry ve Klein, H. J. (1998). The effects of perceived loafing and defensive impression management on group effectiveness. Small Group Research, 29(3), 394-415. doi:10.1177/1046496498293006

Murphy, S. M., Wayne, S. J., Liden, R. C. ve Erdogan, B. (2003). Understanding social loafing: The role of justice perceptions and exchange relationships. Human Relations, 56(1), 61-84. doi:DOI:10.1177/0018726703056001450

Naji, M., Taboli, H. ve Zolfaghari, A. (2012). Relationships between organizational factors and political behaviour tactics in the 1slamic republic of Iran: Kerman province. Intemational Joumal of Economics and Finance, 4(6), 108115.

Olcay, A., Ertürk, M. ve Geylan, C. (2018). Otel işletmelerinde çalışanların algıladıkları sosyal kaytarma düzeyi: Gaziantep otellerinde bir uygulama. Uluslararası Sosyal Araștırmalar Dergisi, 11(56), 1101-1119.

Özdemir Yaylacı, G. (2006). Organizasyonlarda kişilerarası ilişkilerde etki taktikleri ve kullanımına ilişkin literatür çalıșması. Bilig(36), 93-112.

Pfeffer, J. (1981). Power in organizations. Boston: Pitman.

Podsakoff, P. M., MacKenzie, S. B., Lee, J. Y. ve Podsakoff, N. P. (2003). Common method biases in behavioral research: a critical review of the literature and recommended remedies. Journal of Applied Psychology, 88(5), 879903.

Schnake, M. (1991). Equity in effort: The "sucker effect" in coacting groups. Journal of Management, 17, 41-56.

Simms, A. ve Nichols, T. (2014). Social loafing: A review of the literature. Journal of Management Policy and Practice, 15(1), 58-67.

Sünnetçioğlu, S., Korkmaz, H. ve Koyuncu, M. (2014). Konaklama işletmelerinde algilanan örgüt kültür tipinin çalışanların sosyal kaytarma davranışlarını algılamasına etkisi üzerine bir araştırma. Mustafa Kemal Üniversitesi Sosyal Bilimler Enstitüsü Dergisi, 11(28), 17-34.

Şeşen, H., Soran, S. ve Caymaz, E. (2014). Dark side of organizational citizenship behavior (OCB): Testing a model between OCB, social loafing and organizational commitment. International Journal Of Business And Social Science, 5(5), 125-135.

Tan, H. H. ve Tan, M. L. (2008). Organizational citizenship behavior and social loafing: The role of personality, motives, and contextual factors. The Journal Of Psychology, 142(1), 89-108.

Thacker, R. A. ve Wayne, S. J. (1995). An examination of the relationship between upward influence tactics and assessments of promotability. Journal of Management, 21, 739-756.

Thanh, V. B. ve Toan, N. V. (2018). The relationship between organizational justice and social loafing in Ho Chi Minh City, Vietnam. Journal of Asian Finance, Economics and Business, 5(3), 179-183.

Turunç, Ö. (2015). İş stresi - kaytarma ilişkisinde liderin rolü: turizm sektöründe bir araştırma. Uluslararası İktisadi Ve İdari Bilimler Dergisi, 1(2), 142-159.

Uslu, Y. D. ve Çavuş, M. F. (2014). Örgütsel adalet ve kaytarma davranışları. Ordu Üniversitesi Sosyal Bilimler Enstitüsü, $8(9), 51-54$.

Wall, V. D. ve Nolan, L. L. (1987). Small group conflict: A look at equity, satisfaction, and styles of conflict management. Small Group Behavior, 18, 188-211.

Wayne, S. J. ve Kacmar, K. M. (1991). The effects of impression management on the performance appraisal process. Organizational Behavior and Human Decision Processes, 48, 70-88.

Williams, K. D. ve Karau, S. J. (1991). Social loafing and social compensation: The effects of expectations of coworker performance. Journal of Personality and Social Psychology, 61(4), 570-581.

Yakın, B. ve Sökmen, A. (2018). Sosyal kaytarmanın örgütsel sinizme etkisinde zorunlu vatandaşlık davranışının aracılık rolü: Sosyal ağ gruplarında bir araştırma. Ankara Hacı Bayram Veli Üniversitesi İktisadi ve İdari Bilimler Fakültesi Dergisi, 20(2), 399-416.

Yıldız, M. L., İşçi, E. ve Taşçı, S. (2016). İzlenim yönetimi taktiklerinin sosyal kaytarma üzerine etkisi: sağlık sektöründe bir araştırma. İstanbul Kemerburgaz Üniversitesi Sosyal Bilimler Dergisi, 1(1), 103-120.

\section{EXTENDED ABSTRACT}

Organizational justice is a perception based on the distribution of punishment and rewards in the organization, how this distribution is decided and, the quality of the relations with the managers (Colquitt et al., 2013). The perception of organizational justice is an important variable affecting the attitudes and behaviors of employees such as organizational commitment, organizational citizenship, psychological capital, intention to quit, contrary workplace behavior, absenteeism (Cohen-Charash \& Spector, 2001; Harris, Andrews, \& Kacmar, 2007; Colquitt and others, 2013; Colquitt, Long, Rodell, \& HalvorsenGanepola, 2015; Mert \& Sen, 2019). Understanding how organizational perception is formed due to the effect of perception of justice on employee attitudes and behaviors is an important issue for increasing organizational effectiveness. 
Social loafing is defined as the fact that the individual does not perform normally when working in a group (George, 1992). Perceived social loafing is employee perception that other coworkers show less effort in the group than they would individually show (Comer, 1995). Social loafing and perceived social loafing are different concepts.

Political behavior can be expressed as the behaviors of individuals in different interest groups to gain strength and protect their own interests (Ferris et al., 2007). Employees may tend to act politically in order to change distribution decisions in their favor and to avoid punishment and unwanted duties.

The large number of employees, especially in large-scale public organizations, is a reason that enables social loafing behavior by enlarging working groups and reducing task visibility (Liden, Wyne, Jaworski, \& Bennett, 2004). Employees, who perceive that their coworkers do less than they normal do, can reduce their efforts because of the "sucker effect" (Kerr, 1983). Employees may exhibit political behavior in order to avoid the negative consequences of this situation and to influence the manager's distribution decisions in their favor.

The subject of this study is to investigate the organizational justice perception of employees who perceive that their coworkers are making less effort than normal, and the role of political behaviors in the relationship between perceived social loafing and organizational justice.

This study is a cross-sectional study and the data were collected by the convenience sampling method. Harman's single-factor analysis was used to determine the common method variance problem. According to the Harman's single-factor test result, there is no common method variance problem (Podsakoff, MacKenzie, Lee, \& Podsakoff, 2003). The scales are prepared as a five-point Likert (1= completely disagree, $5=$ completely agree). The distribution justice dimension of the organizational justice scale developed by Moorman (1991) was used to measure the perception of justice. The scale developed by George (1992) and adapted by Güçer et al. (2017) was used to measure the perception of social loafing. The political behavior scale developed by Kipnis and Schmidt (1988) was used to determine the political behavior of employees.

Confirmatory factor analysis, convergent and, discriminant validity indicated the measurement model validity and Cronbach Alpha showed internal reliability of scales.

Table 3 presents the mean, standard deviation and, correlation values of the variables. The means of perceived social loafing and organizational justice are lower than the average value (3). The political behavior's mean is approximately average. Perceived social loafing has a significant and negative moderate relationship with organizational justice perception and, no significant relationship with political behavior. Organizational justice perception has a significant and positive relationship with political behavior.

According to the regression analysis result, perceived social loafing negatively affected the perception of organizational justice $(\beta=-0,598, F=173,247, p<0,001)$. Perceived social loafing explained $43 \%$ of the variance change in the perception of organizational justice. To examine the moderating effect of political behavior, the interaction variable included in the regression model at the second stage. The change in R2 is significant $(\Delta \mathrm{R} 2=0.030, \mathrm{~F}=22,139, \mathrm{p}<0.0001)$. According to these results, hypotheses 1 and 2 of the study were accepted.

For interpreting the moderating effect, the interaction graph has been drawn according to \pm 1 SD. This graph shows that a high political behavior skill strengthens the organizational justice perception and, a low political behavior skill weakens the organizational justice perception.

This study showed that perceived social loafing predicted organizational justice negatively and significantly. When individuals consider that their co-worker do not perform their duties or do not perform normally while in the group, the perception of organizational justice is negatively affected by this situation, in other words, the perception of injustice may happen.

When the findings of the study are evaluated within the scope of the sample, it is seen that the participants' perception of organizational justice is low. This result can be interpreted as the participants perceive the distribution decisions in their institutions as unjust. Also, perceived social loafing is low. It can be interpreted that the cooperative (teamwork) working environment is good and that everyone performs his or her duty. It is seen that political behavior is perceived to be close to the average level. The perception of justice decreases when the participants perceive that their co-workers are loafing. When 


\section{KÖKSAL}

Algilanan Sosyal Kaytarmanın Örgütsel Adalete Etkisi: Politik Davranışı Düzenleyici Rolü

perceived social loafing is high, employees with high political skill can influence the distribution decisions of managers and perceive their institutions as more fair than non-political employees perceive. 